\title{
Das Antikorruptionsgesetz - was Sie als Zahnarzt wissen sollten
}

\author{
Im April hat der Bundestag das Gesetz zur Bekämpfung von Korruption im Gesundheitswesen beschlos- \\ sen und viele Auslegungs- und Zweifelsfragen hinterlassen. Bei Zahnärzten rückt nun vor allem die \\ Beziehung zum Dentallabor in den Fokus.
}

\section{Dr. Jens-Peter Damas // Berlin}

$\mathrm{D}$ e Grundidee der Tatbestände im neuen Antikorruptionsgesetz liegt darin, ein Verhalten zu sanktionieren, bei dem ein Angehöriger eines Heilberufs sich von ökonomischen Interessen hat leiten lassen und nicht von einer Entscheidung allein im Patienteninteresse. Bestraft wird, wer als Heilberufler einen anderen im Wettbewerb bevorzugt und dafür einen Vorteil erhält. Die Bevorzugung muss stattfinden

1. bei der Verordnung von Arznei-, Heil- oder Hilfsmitteln oder von Medizinprodukten;

2. bei dem Bezug von Arznei-, Heil- oder Hilfsmitteln oder Medizinprodukten, die jeweils zur unmittelbaren Anwendung durch den Heilberufsangehörigen oder einen seiner Berufshelfer bestimmt sind; oder

3. bei der Zuführung von Patienten oder Untersuchungsmaterial.

Neben dem Heilberufler, der einen anderen bevorzugt, macht sich auch derjenige strafbar, der dem Heilberufler den Vorteil gewährt hat.

\section{Zahnarzt und Labor}

Die vom Zahnarzt geschuldete zahnmedizinische Behandlung umfasst grundsätzlich auch die Beschaffung der erforderlichen Materialien und zahntechnischen Leistungen. Der Zahnarzt ist dabei frei, ob er ein Eigenlabor, eine Laborgemeinschaft oder ein Fremdlabor nutzt.

Auch wenn die Anfertigung des Zahnersatzes aus der zahnärztlichen Praxis ausgelagert wird und Dritte eingebunden werden, trägt der Zahnarzt die Verantwortung für die Lieferung der Prothesen. Der Zahnarzt schließt zivilrechtlich zwei Verträge ab: einen Behandlungsvertrag mit dem Patienten und einen Werkvertrag mit dem (externen) Zahntechniker. In diesen Konstellationen liegt weder eine Verordnung der zahntechnischen Leistungen durch den Zahnarzt noch eine Zuweisung des Patienten an einen bestimmten Zahntechniker vor.

Problematisch kann aber die Tatvariante des Bezugs sein. Eine unlautere Bevorzugung des Fremdlabors durch den Zahnarzt liegt zum Beispiel vor, wenn der Zahnarzt für die Prothesen Kick-back-Zahlungen erhält, die er privat vereinnahmt und nicht an die Patienten weitergibt.

Bevorzugung beim Bezug von Arznei-, Heil- oder Hilfsmitteln oder Medizinprodukten

Die Korruptionsgesetzgebung erfasst auch den Bezug von Arznei- und Hilfsmitteln und Medizinprodukten, die der Heilbe-

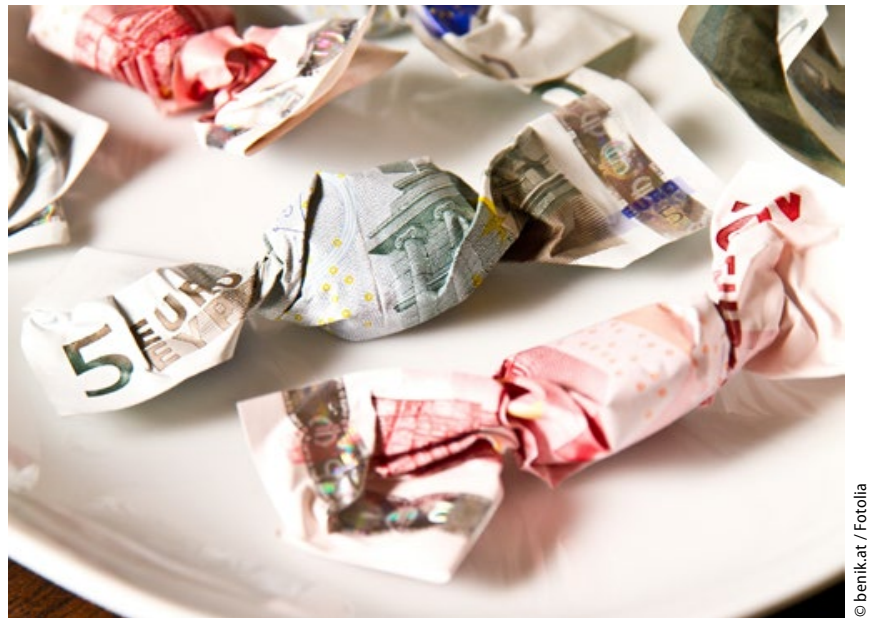

rufsangehörige (zunächst) nicht verordnet, sondern ohne Verordnung unmittelbar beim oder am Patienten anwendet, wie zum Beispiel Prothesen, Implantate und unmittelbar vom Heilberufsangehörigen anzuwendende Arzneimittel.

Eine Strafbarkeit entfällt allerdings nach der Gesetzesbegründung, wenn der Heilberufsangehörige die ihm beim Bezug gewährten Rabatte und sonstigen Vorteile zugunsten des Patienten bzw. des zuständigen Kostenträgers annimmt, um sie an diesen weiterzureichen. Derartige Rabatte dienen dem Wettbewerb und sind im Sinn des Patienten bzw. Kostenträgers.

Kein zulässiger Rabatt ist dagegen das Angebot von einem Dentallabor, einen Scanner zum erheblich verminderten Preis für die Verpflichtung zur Abnahme einer Mindestmenge an Zahnersatzeinheiten erwerben zu können.

\section{Ausgliederung des Labors auf eine $\mathrm{GmbH}$}

Die Auslagerung des Eigenlabors auf eine $\mathrm{GmbH}$ ist aber strafrechtlich nicht zu beanstanden, weil hier der Aspekt der wirtschaftlichen Identität eingreift.

Das Gesetz fordert zur Tatbestandserfüllung, dass von dem Zahnarzt ein anderer unlauter bevorzugt wird. Die Ausgliederung des Labors in eine GmbH soll dem Zahnarzt aber nicht zum Nachteil gereichen. Das Strafrecht will unseres Erachtens den Zahnarzt nicht zwingen, alle seine Aktivitäten in seinem Einzelunternehmen zu betreiben, nur um keinen „anderen“ (als $\mathrm{GmbH}$ ) im Sinn des Tatbestands zu schaffen. Das heißt, der bevorzugte Einkauf der Laborleistungen beim eigenen Betrieb stellt dann keine unlautere Bevorzugung gegenüber Dritten dar, wenn der Zahnarzt zu 100 Prozent an dem Labor beteiligt ist.

Dr. Jens-Peter Damas ist Fachanwalt für Steuerrecht und Mitglied der Geschäftsleitung der Beratergruppe ETL ADVISION. 